\title{
100 Years for Curve of Monson and Still Relevant
}

\author{
Pravinkumar G Patil \\ International Journal of Prosthodontics and Restorative Dentistry (2021): 10.5005/jp-journals-10019-1325
}

Curve of Monson is defined as a proposed ideal curve of occlusion in which each cusp and incisal edge touches or conforms to a segment of the surface of a sphere $8^{\prime \prime}$ in diameter with its center in the region of the glabella. ${ }^{1}$ This curve was popularly known by the name of George S Monson, dentist, Minnesota, USA when he first mentioned it in 1920. ${ }^{2}$ Today, we are in the year 2021 and the curve of Monson, also alternately known as a Monson's spherical theory, is still relevant in dental restorative procedures especially in Prosthodontics and Orthodontics. In the theory that occlusion should be spherical, the curve of Spee (anteroposterior curve) and the curve of Wilson (Mediolateral curve) have also been described and assumed to be the part of the curve of Monson while determining the normal occlusal plane in dental treatments. ${ }^{1-4}$ The curve of Wilson, when viewed in the frontal plane, is concave in the mandibular arch and contacts the buccal and lingual cusp tips of the mandibular molars; and is convex in the maxillary arch and contacts the buccal and lingual cusp tips of the maxillary molars. ${ }^{1,3}$ The curve of Spee is the anatomic curve established by the occlusal alignment of the teeth, as projected onto the median plane, beginning with the cusp tip of the mandibular canine and following the buccal cusp tips of the premolar and molar teeth, continuing through the anterior border of the mandibular ramus, ending with the anterior-most portion of the mandibular condyle. ${ }^{1,4}$

Uneven occlusal plane is a common clinical occurrence, which may be caused by supraeruption, wear, or drifting of the teeth. ${ }^{5}$ In such situations, achieving the normal occlusal plane becomes a primary objective of any dental restorative procedure to facilitate natural mandibular movements and mastication. ${ }^{5-9}$ The curve of Spee permits total posterior disocclusion on the mandibular protrusion given proper anterior guidance and the curve of Wilson permits lateral mandibular excursion free from posterior interferences. ${ }^{2-4}$ Many devices and techniques have been described to evaluate and correct the occlusal plane based on the principles of these three curves (curve of Monson, curve of Wilson, and the curve of Spee) including the Broadrick occlusal plane analyzer (BOPA), ${ }^{1,8,9}$ Yurkstas metal occlusal template, ${ }^{10}$ custom-made occlusal plane template (OPT), 5,7,11 and the self-grinding OPT. ${ }^{6}$ The BOPA is an eponym for a flag-like component attached superiorly to the upper member of an articulator; the technique incorporates Monson's spherical theory of occlusion to develop the occlusal plane; a compass is used to scribe two intersecting arcs with a 4" radius; centers of rotation are located at the canine cusp tip and the distobuccal cusp tip of the second molar; the point of bisection of the arcs that are scribed on the Broadrich analyzer determines the center of rotation for the arc with a 4" radius that determines the occlusal plane. Similarly, the Yurkstas metal occlusal template or the custom-made OPTs have also been described and successfully being used in restorative procedures to normalize the deranged occlusal plane..$^{5-7,10,11}$ Single complete denture (SCD) is a challenging clinical situation when the opposing natural dentition is not in a normal plane of occlusion. ${ }^{12}$ In such situations, the malaligned,
Department of Prosthodontics, Division of Restorative Dentistry, School of Dentistry, International Medical University, Kuala Lumpur, Malaysia

Corresponding Author: Pravinkumar G Patil, Department of Prosthodontics, Division of Restorative Dentistry, School of Dentistry, International Medical University, Kuala Lumpur, Malaysia, Phone: +601135022042, e-mail: pravinandsmita@yahoo.co.in

How to cite this article: Patil PG. 100 Years for Curve of Monson and Still Relevant. Int J Prosthodont Restor Dent 2021;11(3):110-111.

Source of support: Nil

Conflict of interest: None

tilted, or supra-erupted teeth in the opposing arch must be corrected beforehand to achieve a balanced occlusion for the SCD and these devices ${ }^{5-11}$ provide vital guidelines in normalizing the occlusal plane.

Nam et al. ${ }^{13}$ generated and measured the three-dimensional (3D) Monson's sphere and curve of Wilson using virtual dental models of 79 Korean young adults and found out that the radius of the curve of Monson's was greater than the original 4" value suggested by Monson. Similar studies have been carried out in Japanese ${ }^{14}$ and Indian ${ }^{15}$ populations and suggested that ethnic differences exist in the radius or diameter of Monson's sphere, and eventually the curve of Spee, and curve of Wilson. Even though it has been 100 years for the curve of Monson when it was first described in $1920{ }^{2}$ it is still popularly known, referred to, and used for prosthetic reconstruction and orthodontic treatments $s^{5-7,10,11,13}$ as well as in research studies. ${ }^{13-18}$ Further clinical studies are encouraged in this area to generate, measure, and analyze the occlusal curvatures including Monson's sphere, the curve of Spee, and the curve of Wilson especially using current advanced technologies and developments in digital dentistry.

\section{References}

1. The glossary of prosthodontic terms. J Prosthet Dent 2005;94(1):1092. DOI: 10.1016/j.prosdent.2005.03.013.

2. Monson GS. Occlusion as applied to crown and bridgework. J Nat Dent Assoc 1920;7(5):399-417. DOI: 10.14219/jada.archive.1920. 0071.

3. Wilson GH. A manual of dental prosthetics. Philadelphia: Lea \& Febiger; 1911. pp. 22-37.

4. Spee FG. Die verschiebrangsbahn des unterkiefers am schadell. Arch Anat Physiol (Leipz) 1890;16:285-294.

5. Foong KW, Patil PG. Fabrication of maxillary single complete denture in a patient with deranged mandibular occlusal plane: a case report. Saudi Dent J 2019;31(1):148-154. DOI: 10.1016/j.sdentj.2018.10.007.

6. Patil PG, Nimbalkar S. A self-grinding occlusal plane template to help modify an uneven occlusal plane before providing definitive restorations. J Prosthet Dent 2021;125(3):551-553. DOI: 10.1016/j. prosdent.2020.03.002. 
7. Muley BY, Patil PG, Khalikar AN, et al. Simple technique to fabricate custom made occlusal plane template. J Indian Prosthodont Soc 2014;14(Suppl. 1):S334-336. DOI: 10.1007/s13191-013-0308-0.

8. Lynch CD, McConnell RJ. Prosthodontic management of the curve of spee: use of the broadrick flag. J Prosthet Dentis 2002;87(6):593-597. DOI: $10.1067 / \mathrm{mpr} .2002 .125178$.

9. Bedia SV, Dange SP, Khalikar AN. Determination of the occlusal plane using a custom-made occlusal plane analyzer: a clinical report. J Prosthet Dent 2007;98(5):348-352. DOI: 10.1016/S0022-3913(07)60118-8.

10. Yurkstas AA. Single dentures. In: Sharry JJ, ed. Complete denture prosthodontics. 2nd ed., New York: McGraw-Hill; 1968. p. 300.

11. Baker PS, Londono J. Method for fabrication of a custom occlusal template. J Prosthet Dent 2008;99(6):492-493. DOI: 10.1016/S00223913(08)60115-8.

12. Lauciello FR. Single complete maxillary denture. In: Winkler S, ed. Essentials of complete denture prosthodontics. 2nd Ed. St. Louis: Ishiyaku Euroamerica; 1994. pp. 417-426.

13. Nam SE, Park YS, Lee W, et al. Making three-dimensional monson's sphere using virtual dental models. J Dent 2013;41(4):336-344. DOI: 10.1016/j.jdent.2013.01.003.
14. Kagaya K, Minami I, Nakamura T, et al. Three-dimensional analysis of occlusal curvature in healthy Japanese young adults. J Oral Rehabilitat 2009;36(4):257-263. DOI: 10.1111/j.1365-2842.2008. 01930.x.

15. Surendran SV, Hussain S, Bhoominthan S, et al. Analysis of the Curve of Spee and the Curve of Wilson in adult Indian population: a three-dimensional measurement study. J Indian Prosthodont Soc 2016;16(4):335-339. DOI: 10.4103/0972-4052.191290.

16. Baydas B, Yavuz I, Atasaral N, et al. Investigation of the changes in the positions of upper and lower incisors, overjet, overbite, and irregularity index in subjects with different depths of Curve of Spee. Angle Orthodont 2004;74(3):349-355. DOI: 10.1043/00033219(2004)0742.0.CO;2.

17. Nam SE, Kim YH, Park YS, et al. Three-dimensional dental model constructed from an average dental form. Am J Orthodont Dentofac Orthoped 2012;141(2):213-218. DOI: 10.1016/j.ajodo.2011. 06.038.

18. Ferrario VF, Sforza C, Miani A. Statistical evaluation of monson's sphere in healthy permanent dentitions in man. Archiv Oral Biol 1997;42(5):365-369. DOI: 10.1016/s0003-9969(97)00021-6. 